\title{
EFFECT OF SHADING WITH TREES TO IMPROVE LOCAL TEMPERATURE CONDITIONS
}

\author{
Van Doan Cao, Pavel Kic \\ Czech University of Life Sciences Prague, Czech Republic \\ caodoan2006@gmail.com,kic@tf.czu.cz
}

\begin{abstract}
Planting trees in living environments can mitigate outdoor thermal stress and reduce solar radiation to the surfaces of buildings as well. Modification of outside microclimates using certaintypes of tree cover can provide important benefits to the space around trees or walls of buildings. However, how beneficial is each type of trees, is not clear. The aim of this paper is to present the measured results of solar radiation, globe temperature, surface temperature, air temperature in the shade of typical trees cultivated in the living area inside cities. The measured results are compared with the same measurements of unshaded surfaces. Based on the obtained results, the cooling effect andthe largest benefit of the tree canopy of several tree species can be evaluated. For this research five distinct areas shaded by individual grown trees or groups of trees (Paulownia tomentosa, Acer saccharinum, Picea pungens "Glanca", Carpinus betulus, Tilia platyphyllos and Acer platanoides) were selected. The measurements were carried out during very hot summer days with average air temperatures from 35 to $40{ }^{\circ} \mathrm{C}$ and solar radiation from 700 to $1,000 \mathrm{~W} \cdot \mathrm{m}^{-2}$. The coverage of the canopy does not only benefitthe space under the trees, but also influences the reduction in the air temperature as well as radiation of the texture of buildings close to the trees. Direct solar radiation under trees in the shaded areas were reduced from79.4 to $94.4 \%$ of unshaded conditions. Therefore, it contributes to reducingthe air temperature inside the building in summer in sunlight. The reduction in the air temperature under different species of trees is not the same. For example, under the cluster Tilia platyphyllos and Acer platanoides, the reduction in the air temperature was $20.8 \%$, while under the tree Carpinus betulus, it was $13.7 \%$. This study clearly demonstrates the microclimate benefits of the air temperature reduction under the canopy of certain types of trees and provides guidance for residential planners in strategic tree planting.
\end{abstract}

Keywords: air temperature, canopy, solar radiation, surface temperature.

\section{Introduction}

Planting trees is a good solution for improving thermal comfort in cities. The shade cast by trees and the amount of radiation filtered are influenced by the form and density of the canopy. The amount of radiation intercepted depends on the density of the twigs, branches, and leaf cover. These elements influence the overall characteristics of the tree shape and density $[1 ; 2]$. Tree shade qualities are also influenced by the individuality of the trunks and leaves, which should be considered [1;3].

Effect of the three dimensional nature of trees; as well as having a cool canopy, they also shade adjacent areas. This is important for two reasons. First, it will reduce the surface temperature of the shaded area, reducing its storage and convection of heat; to quantify the regional cooling role of trees it is important to measure this effect. Second, shading affects human comfort, since it will alter our perceived temperature, which is dependent more on the radiation flow between ourselves and the local environment than on convection [4].

Several empirical and modelling studies have demonstrated that shade trees can provide significant summer energy savings when strategically located and maintained near buildings $[5 ; 6]$. Similarly, improved building thermal regulation can go some way to protecting vulnerable sections of society from heat stress, stroke or mortality. The net radiation received by building walls and roof surfaces is a primary driver of building microclimates [7].

Tree canopies absorb and reflect large proportions of both solar and terrestrial radiation received by a building, which in summer can reduce the difference between the internal and external building temperatures and directly reduce the energy use for internal space cooling [8;9]. Shade trees can also influence building microclimates through evapotranspiration and wind control [10;11], however, a reduction in solar irradiance received is the most effective way to reduce building external wall surface temperatures in summer [12].

The aim of this research paper is to show the cooling effect and shading effect of tree shade from various tree species in different planting configurations on solar radiation, globe temperature, surface temperature and air temperature. The surface temperature will be greatly influenced by the amount and quality (intensity) of the tree canopy shade. Percentage shade cover obviously provides a good 
indication of the amount of shade, whilst solar radiation received on the surface is an indication quality of the shade. Based on the obtained results, the benefit by tree canopy of several tree species will be evaluated for practical recommendations.

\section{Materials and methods}

This research work and measurements were carried out at the Czech University of Life Sciences (CULS) in Prague. The CULS is located in the north of Prague, Czech Republic. Prague $\left(50^{\circ} 05 \mathrm{~N}\right.$, $14^{\circ} 25 \mathrm{E}, 286 \mathrm{~m}$ elevation) in a temperate climate. During the summer season, which is June to August, it is usually warm. According to the meteorological station, the local air temperature was $29.6 \pm 0.5^{\circ} \mathrm{C}$ during the measurement time.
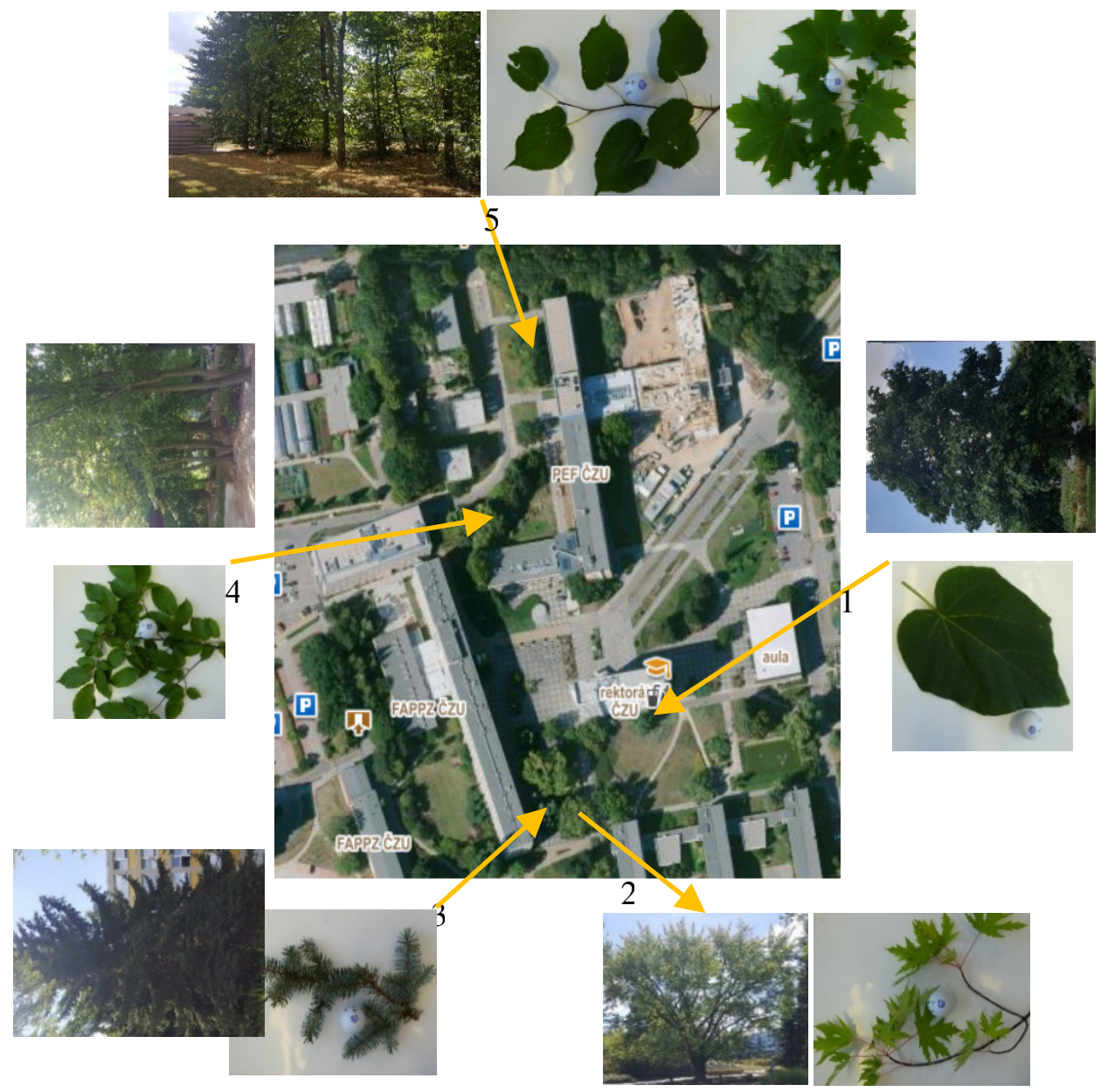

Fig. 1. Tree species with leaf shape and their locations in measurements:

1 - Paulownia tomentosa; 2 - Acer saccharinum; 3 - Picea pungens "Glanca"; 4 - Carpinus betulus; 5 - Tilia platyphyllos and Acer platanoides

Temperature in the shade and in the sunlight were measured by the FPA 805 GTS globe thermometer (with an operative range from -50 to $+200{ }^{\circ} \mathrm{C}$, an accuracy of $\pm 0.1^{\circ} \mathrm{C}$ and a diameter of $0.15 \mathrm{~m}$ ) together with the temperature of the surrounding air measured by the FHA 646-21 sensor including the NTC type $\mathrm{N}$ temperature sensor with an operative range from -30 to $+100{ }^{\circ} \mathrm{C}$ with an accuracy of $\pm 0.1^{\circ} \mathrm{C}$.

Furthermore,the intensity of solar radiation was measured by the FLA 613-GSglobal radiation probe head witha measuring range from 0 to approx. $1200 \mathrm{~W} \cdot \mathrm{m}^{-2}$, spectral sensitivity from $400 \mathrm{~nm}$ to $1100 \mathrm{~nm}$ and absolute error $<10 \%$.

Air temperature, globe temperature and solar radiation measurements were conducted at $0.4 \mathrm{~m}$ height in the afternoon before 1 p.m. to 3 p.m.in quite clear, cloudless time ( $25^{\text {th }}$ July 2018$)$. We set up the measuring equipment under each individual tree and tree clusters during around 15 minute period when it was sunny. All these data were stored at intervals of one minute on the ALMEMO 2590 
measuring instrument (in the shade) and ALMEMO 2890 (in the sun).Measurements of air temperature and solar radiation in the shade and in the sunlight were made simultaneously.

Table 1

Description of the basic characteristics of the tree species

\begin{tabular}{|c|c|c|c|c|}
\hline Tree species & Disposition & $\begin{array}{c}\text { Canopy } \\
\text { width, m }\end{array}$ & $\begin{array}{c}\text { Tree } \\
\text { height, m }\end{array}$ & $\begin{array}{c}\text { Measured time, } \\
\text { p.m. }\end{array}$ \\
\hline Paulownia tomentosa & Individual & 9 & 13 & $0: 45-1: 00$ \\
\hline Acer saccharinum & Individual & 18 & 15 & $1: 05-1: 20$ \\
\hline Picea pungens "Glanca" & Individual & 8 & 16 & $1: 25-1: 40$ \\
\hline Carpinus betulus & Cluster & $18 \times 30$ & 12 & $1: 55-2: 10$ \\
\hline $\begin{array}{c}\text { Tilia platyphyllos and } \\
\text { Acer platanoides }\end{array}$ & Cluster & $22 \times 45$ & 14 & $2: 35-2: 50$ \\
\hline
\end{tabular}

The surface temperatures on the building walls and on the grounds were measured by the IR Flexcam Pro thermographic camera with an operative range from -30 to $+350{ }^{\circ} \mathrm{C}$ with an accuracy of $\pm 2{ }^{\circ} \mathrm{C}$. Instantaneous values of surface temperatures (thermograms) were stored in the device memory and then analysed in a PC using the special Infrared Solutions FlexView 1.2.2 software designed for this thermographic camera.

The attenuation of solar radiation was dependent on the tree features such as the density of the twigs and branches, and leaf cover. The percentage of radiation attenuated by each tree, or cluster of trees, was obtained by the method of [13], where measurements of solar radiation in the shade and in the sunlight were made simultaneously, in accordance with the expression:

$$
A t=\frac{S_{\text {sun }}-S_{\text {shade }}}{S_{\text {sun }}} \cdot 100,
$$

where $A t-$ solar radiation attenuation, \%;

$S_{\text {sun }}$ - incident energy in the sun, $\mathrm{kWh} \cdot \mathrm{m}^{-2}$

$S_{\text {shade }}$ - incident energy in the shade, $\mathrm{kWh} \cdot \mathrm{m}^{-2}$.

From the measurements of each tree species carried out in different time periods, the temperature measured inthe sun was adopted as the normalization parameter, so that the shading effect of each tree could be quantified. By the method of [13], the relative variation of the air temperature was calculated by the expression:

$$
R V t=\frac{t_{\text {sun }}-t_{\text {shade }}}{t_{\text {sun }}} 100,
$$

where $R V t-$ relative variation of air temperature, \%;

$t_{\text {sun }}$ - air temperature in the sun, ${ }^{\circ} \mathrm{C}$;

$t_{\text {shade }}$ - air temperature in the shade, ${ }^{\circ} \mathrm{C}$.

Similar calculations were carried out for globe temperatures. For each tree species, the average of the attenuation and temperature were calculated for a measured period, as well as the corresponding standard error. The relative variations were also temperature reductions that were calculated by percentage values.

The obtained results of the air temperature and relative humidity, as well as the daylight measurements, were processed by Excel software and verified by the Statistica 12 statistical software (ANOVA and TUKEY HSD Test) to recognise if the differences are significant.

Different superscript letters $(a, b, c)$ in common are significantly different from each other in the columns of the tables (ANOVA; Tukey HSD Test; $P \leq 0.05$ ), e.g. if there is the same superscript letter in the rows (different trees species) of the column, it means the differences between the tested values of different trees are not statistically significant at the significance level of 0.05 . 


\section{Results and discussion}

The measurement results from the research show solar radiation together with the external air temperature in the university campus during the summer day when the sky was quite clear, cloudless. Then, the obtained results in the shade and in the sun were compared with each other to analyse the influences of the tree canopies on the space around them.

The relative variation of air temperature, globe temperature and attenuation of solar radiation in the shade of five tree species and in the sun are presented in Table 2.Different letters $(a, b, c)$ in the superscript are the sign of high significant differences (ANOVA; Tukey HSD Test; $P \leq 0.05$ ) between the conditions in the shade of different trees.

Table 2

Differences between results in the shade and in the sun

\begin{tabular}{|l|c|c|c|c|}
\hline \multirow{2}{*}{ Tree species } & \multirow{2}{*}{ Disposition } & $\boldsymbol{R V t}$ & $\boldsymbol{R V t}_{\boldsymbol{g}}$ & $\boldsymbol{A t}$ \\
\cline { 3 - 5 } & & $\% \pm \mathrm{SD}$ & $\% \pm \mathrm{SD}$ & $\% \pm \mathrm{SD}$ \\
\hline Paulownia tomentosa & Individual & $15.2 \pm 2.7^{\mathrm{a}}$ & $28.9 \pm 2.7^{\mathrm{a}}$ & $80.7 \pm 11.8^{\mathrm{a}}$ \\
\hline Acer saccharinum & Individual & $15.2 \pm 1.1^{\mathrm{a}}$ & $26.9 \pm 1.3^{\mathrm{a}, \mathrm{b}}$ & $79.4 \pm 4.5^{\mathrm{a}}$ \\
\hline Picea pungens "Glanca" & Individual & $16.9 \pm 1.1^{\mathrm{a}, \mathrm{c}}$ & $31.5 \pm 3.1^{\mathrm{a}, \mathrm{c}}$ & $92.6 \pm 0.7^{\mathrm{b}}$ \\
\hline Carpinus betulus & Cluster & $13.7 \pm 0.8^{\mathrm{a}, \mathrm{d}}$ & $29.2 \pm 1.4^{\mathrm{a}}$ & $94.4 \pm 0.04^{\mathrm{b}, \mathrm{c}}$ \\
\hline $\begin{array}{l}\text { Tilia } \text { platyphyllos } \text { and } \\
\text { Acer platanoides }\end{array}$ & Cluster & $20.8 \pm 2.6^{\mathrm{b}}$ & $29.7 \pm 7.0^{\mathrm{a}}$ & $86.7 \pm 1.4^{\mathrm{a}, \mathrm{b}}$ \\
\hline
\end{tabular}

SD - Standard deviation

The average air temperature reduction due to the canopy cover was the largest (20.8\% reduction) at Tilia platyphyllos (significantly different from all other trees). Conversely, at Carpinus betulus tree there was the smallest average temperature reduction ( $13.7 \%$ reduction), nevertheless, statistically it was not significant difference between this tree and the results of average temperature reduction at Paulownia tomentosa, Acer saccharinum that respectively were: $15.2 \%, 15.2 \%$. These results show that the cluster Tilia platyphyllos and Picea pungens "Glanca (16.9\% reduction)had the best cooling effect to reduce the air temperature due to their shade.

The globe temperature of these species was also measured and evaluated by the method of [13]. The average globe temperature reductions were larger than average air temperature reductions in the same areas of measurements. Average globe temperature reduction by canopy cover was the largest (31.5\% reduction) at Picea pungens "Glanca" species. Conversely, at Acer saccharinum tree there was the smallest average globe temperature reduction ( $26.9 \%$ reduction). The difference between the effects of these two trees on RVtg was statistically significant. The statistical evaluation of all trees together did not show statistically significant differences between RVtg. These results show that the cooling effect to reduce the globe temperature with their shading were greater than the cooling effect to reduce the air temperature, which can be explained by the long-time acting shadow of Picea pungens "Glanca".

Unlike the air temperatures, the globe temperatures increased and decreased quickly; they reached high temperatures more quickly and showed a higher level of variability than the air temperatures, then increased rapidly in the corresponding shade. The globe thermometers in the sun increased to peaks around $44-55^{\circ} \mathrm{C}$, it was around $10-15^{\circ} \mathrm{C}$ hotter than the air temperature. In contrast, the globe temperatures were only $2.5^{\circ} \mathrm{C}$ hotter than the air in the shade. This pattern was seen on all measured time periods. It can be seen that there were much lower differences between the maximum globe temperature and maximum air temperature on hot days under the canopies. The main reason was because of solar radiation, which effected the globe thermometer. This fact is important in terms of the effect of shading parts of buildings protected from direct sunlight. The measured results of solar radiation at the same species area are shown in Fig. 2.

During the measured time periods, the direct solar radiations in the sun were from 700 to $1,000 \mathrm{~W} \cdot \mathrm{m}^{-2}$. The solar radiation values under trees in the shaded areas were from 50.5 to $164.9 \mathrm{~W} \cdot \mathrm{m}^{-2}$. From the measured results of each species, we have received attenuation of solar radiation, which was the smallest $79.4 \%$ at Acer saccharinum and Paulownia tomentosa $80.7 \%$, the 
largest $94.4 \%$ at Carpinus betulus. The difference between the effect of Carpinus betuluson At was statistically significant in comparison with the other.

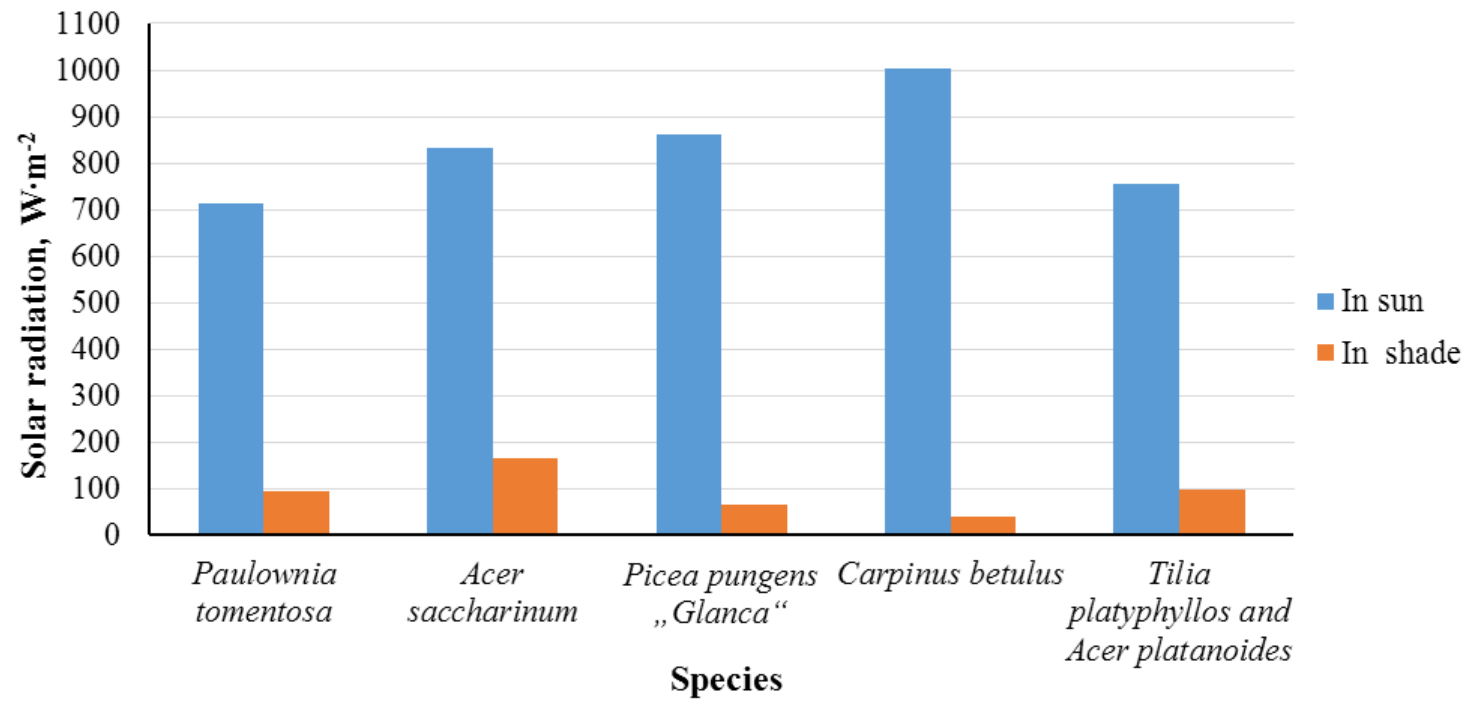

Fig. 2. Solar radiation in shade andsunof five tree species

Reduced solar radiation transmittance in the shades with high-percentage tree canopy cover was very high. This reduction decreases the radiant heat on the surfaces of building walls. Therefore, it contributes to reducing the air temperature inside a building during summer in the sunlight. We also used results from thermography to see more clearly the actual results of the surface temperature in the ground and building walls. Several pictures ofthermography equipment are shown in Fig. 3 together with their values of the surface temperature and corresponding area that are shown in Table 3.

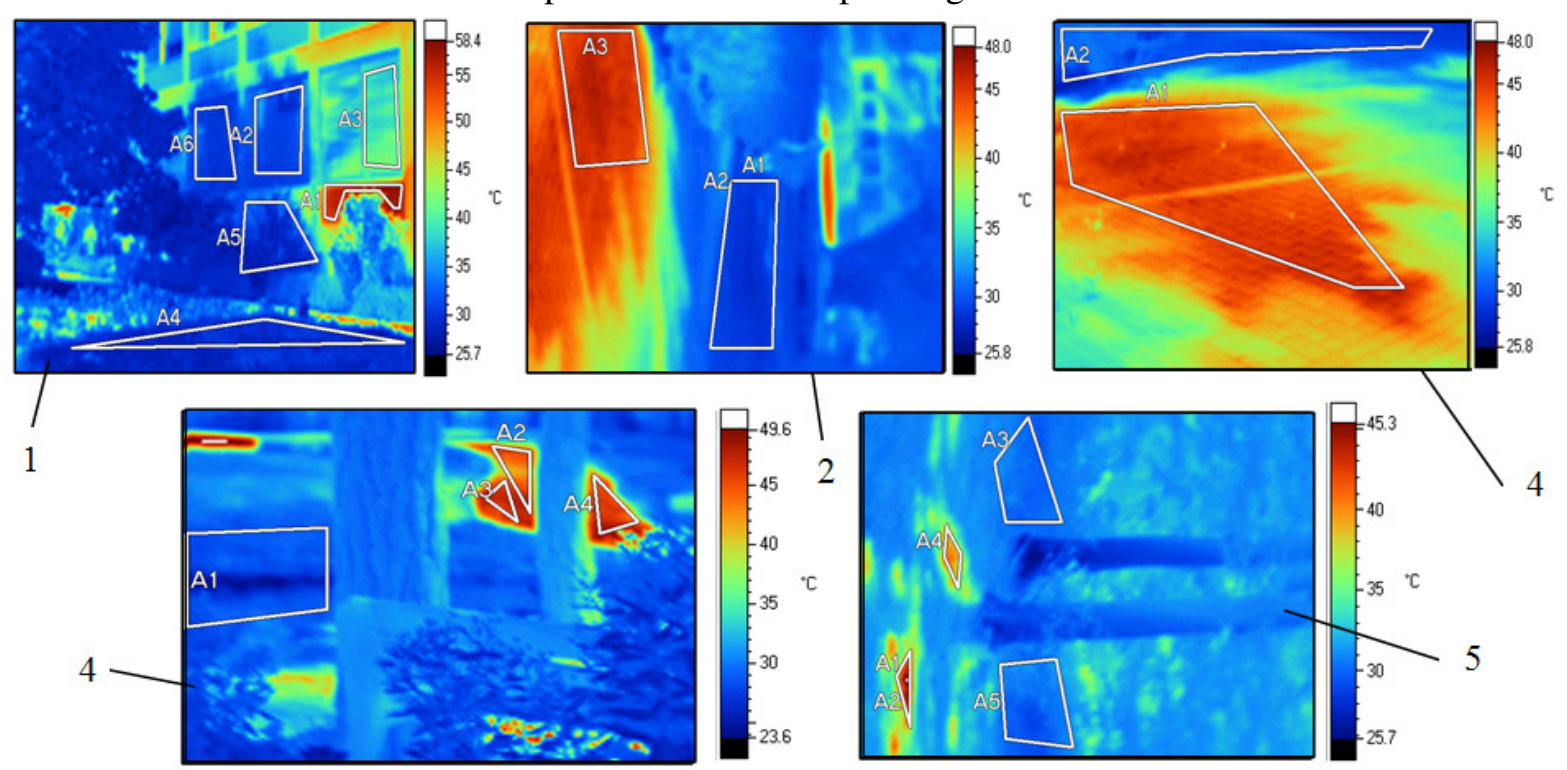

Fig. 3. Images from thermography in shade and sun of five species: 1 - Paulownia tomentosa; 2 - Acer saccharinum; 3 - Picea pungens "Glanca"; 4 - Carpinus betulus; 5 - Tilia platyphyllos and Acer platanoides

From the thermography images and measured surface temperatures it can be seen that the macadam surface was the hottest $\left(45.9^{\circ} \mathrm{C}\right)$. Conversely, in the shade, the macadam temperature was the lowest $\left(28.1^{\circ} \mathrm{C}\right)$. It also means that the effect of solar radiation reduction in shade under Carpinus betulus was the largest $\left(17.8^{\circ} \mathrm{C}\right.$ reducing). The attenuation of solar radiation in shade under Carpinus betulus in the Table 2 is also the biggest ( $94.4 \%$ reducing). This can be explained by specific features of this cluster: the selarge trees were intertwined together with maximal coverage due to their height and width; they have plagiotropic trunks; and small binate leaves. It can be said that the cluster of 
Carpinus betulus species has the greatest coverage percentage. This is a great benefit from the shade of the trees to reduce the surface temperature in the building walls that are built next to the trees.Both concrete areas were warmer than the grass on the ground in the sun, and cooler in the shade. It means that shading reduced the surface temperatures of the concrete surfaces more than that of the grass ground.

Table 3

Surface temperatures in the shade and sun measured by thermography in each tree species

\begin{tabular}{|c|c|c|c|c|c|}
\hline \multirow{2}{*}{ Species } & \multirow{2}{*}{ Disposition } & \multicolumn{2}{|c|}{ Area in sun } & \multicolumn{2}{c|}{ Area in shade } \\
\cline { 3 - 6 } & & $\begin{array}{c}\text { Average value } \\
{ }^{\circ} \mathrm{C} \pm \text { SD }\end{array}$ & $\begin{array}{c}\text { Area in } \\
\text { image }\end{array}$ & $\begin{array}{c}\text { Average value } \\
{ }^{\circ} \mathrm{C} \pm \text { SD }\end{array}$ & $\begin{array}{c}\text { Area in } \\
\text { image }\end{array}$ \\
\hline Paulownia tomentosa & External blinds & $39.7 \pm 1.3$ & $\mathrm{~A} 3$ & $30.9 \pm 0.8$ & $\mathrm{~A} 6$ \\
\hline Acer saccharinum & Concrete & $45.2 \pm 0.7$ & $\mathrm{~A} 3$ & $29.2 \pm 0.5$ & $\mathrm{~A} 1$ \\
\hline $\begin{array}{c}\text { Picea pungens } \\
\text { "Glanca" }\end{array}$ & Concrete & $44.3 \pm 0.9$ & $\mathrm{~A} 1$ & $30.3 \pm 0.6$ & $\mathrm{~A} 2$ \\
\hline $\begin{array}{c}\text { Carpinus betulus } \\
\text { Tilia platyphyllos and } \\
\text { Acer platanoides }\end{array}$ & Macadam & $45.9 \pm 1.1$ & $\mathrm{~A} 4$ & $28.1 \pm 1.2$ & $\mathrm{~A} 1$ \\
\hline
\end{tabular}

SD - Standard deviation

The differences between the average surface temperature in shaded and unshaded areas were always bigger than the air temperature. For example, the average surface difference at Paulownia tomentosa was around $16^{\circ} \mathrm{C}$ in the concrete ground, but the average air temperature difference was around $4.5^{\circ} \mathrm{C}$. These obtained results show that the influence of the canopy on the surface temperatures werelarger than the air temperature. The surface temperature reduction was the biggest benefit from microclimate modification by trees in summer. Therefore, it contributes to reducing the air temperature inside the building during summer in the sunlight.

\section{Conclusions}

1. From our obtained results it can be seen that in outdoor spaces greenery is able to reduce air temperatures and surface temperatures, it contributes to improving local temperature conditions due to their shading. For indoor microclimate, trees hading can reduce the incidence of solar radiation on building facades, improve internal thermal comfort, and conserve the energy spent on refrigeration.

2. These results show that the cluster Tilia platyphyllos and Acer platanoides had the best cooling effect to reduce the air temperature with their shading (20.8\% reduction). The effect to reduce the globe temperature with their shading was greater than the cooling effect to reduce the air temperature (31.5\% reduction at Picea pungens "Glanca"species). The reason was because of the solar radiation effect through the canopy. The size and shape of the tree crown can improve thermal comfort by an air temperature reduction in a microclimate, as can the size and shape of the leaves, trunk, and the permeability of the crown.

3. The attenuation of solar radiation due to the shade of Carpinus betulus was the biggest $(94.4 \%)$. Therefore, the effect of solar radiation reduction in shade of Carpinus betulus was also the biggest, it reduced $17.8^{\circ} \mathrm{C}$ surface temperature that was a maximal surface temperature reduction in comparing with others.

4. The surface temperature reductions were larger thanthe reduction of the air temperature. This is a great benefit of the shade of the trees to reduce surface temperature in the building walls that are built next to the trees. Therefore, it contributes to reducing the air temperature inside the buildings during the summer season, in the sunlight.

\section{References}

[1] Abreu-Harbich L.V., Labaki L.C., Matzarakis A. Different trees and configuration as microclimate control strategy in Tropics. In Proceedings of the international conference on passive and low energy architecture, 2012 Lima, PE,.Lima: PLEA. 
[2] Scudo G. Thermal comfort in green spaces. In Green structures and urban planning. Milan, 2002, [online] [14.02.2019]. Available at: http://www.greenstructureplanning.eu/COSTC11/comfort.htm

[3] Shashua-Bar L., Potchter O., Bitan A., Boltansky D., Yaakov Y. Microclimate modelling of street tree species effects within the varied urban morphology in the Mediterranean city of Tel Aviv, Israel. International Journal of Climatology, vol. 57, 2010, pp. 44-57.

[4] Matzarakis A., Rutz F., Mayer H. Modelling radiation fluxes in simple and complex environments - application of the RayMan model. International Journal of Biometerology, vol. 51 (4), 2007, pp. 323-334.

[5] Akbari H., Kurn D., Bretz S., Hanford J. Peak power and cooling energy savings of shade trees. Energy and Building, vol. 25, 1997, pp. 139-148.

[6] Simpson J.R. Improved estimates of tree-shade effects on residential energy use. Energy and Buildings, vol. 34, 2002, pp. 1067-1076.

[7] Cao V.D., Kic P. Analysis of indoor temperature in the workshop building during the summer: a pilot study. Agronomy research, vol. 16 (4), 2018, pp. 1614-1621.

[8] Laband D.N, Sophocleus J.P. An experimental analysis of the impact of tree shade on electricity consumption. Arboriculture \& Urban Forestry, vol. 35, 2009, 35, pp. 197-202.

[9] Federer C.A. Trees modify the urban microclimate. Journal of Arboriculture, vol. 2, 1976, pp. 121-127.

[10] Herrington L.P. Climatic variables. In: McPherson EG, editor. Energy conserving site design. Washington, D.C.: American Society of Landscape Architects; 1984. pp. 59-77.

[11] Akbari $\mathrm{H}$. Shade trees reduce building energy use and $\mathrm{CO}_{2}$ emissions from power plants. Environmental Pollution, vol. 116, 2002, pp.119-126.

[12] Shashua-Bar L., Hoffman M.E. Vegetation as a climatic component in the design of an urban street-an empirical model for predicting the cooling effect of urban green areas with trees. Energy and Buildings, vol. 31, 2000, pp. 221-235.

[13] Bueno-Bartholomei C. L., Labaki L. C. How much does the change of species of trees affect their solar radiation attenuation? Paper presented at the fifth international conference on Urban Climate, 2003, Lodz, Poland. 